Chronic Obstructive Pulmonary Diseases:

Journal of the COPD Foundation

\author{
Original Research
}

\title{
Treatment Preferences of Patients with Chronic Obstructive Pulmonary Disease: Results from Qualitative Interviews and Focus Groups in the United Kingdom, United States, and Germany
}

Melanie Schroeder, $\mathrm{MSc}^{1}$ Katie Hall, $\mathrm{MPH}^{2}$ Lina Eliasson, $\mathrm{PhD}, \mathrm{CPsychol}^{2}$ Sophia Bracey, $\mathrm{MSc}^{3}$

Necdet B. Gunsoy, $\mathrm{PhD}^{4}$ Jake Macey, $\mathrm{MSc}^{3}$ Paul W. Jones, $\mathrm{PhD}^{5}$ Afisi S. Ismaila, $\mathrm{PhD}^{6,7}$

\section{Abstract}

Background: A wide range of therapeutic regimens, including single-inhaler triple therapies (SITTs), are now available for the maintenance treatment of chronic obstructive pulmonary disease (COPD). Thus, an improved understanding of patient preferences may be valuable to inform physician prescribing decisions. This study was performed to assess the factors considered by patients when making decisions about their COPD treatments using qualitative techniques.

Methods: In the United Kingdom, United States and Germany, individual qualitative interviews ( $\mathrm{n}=10$ per country) and focus groups ( 1 per country; [United Kingdom, n=4; United States, n=6; Germany, n=6 participants]) were conducted. Interviews and focus groups were semi-structured, lasting approximately 60 minutes, and focused on treatment preferences. Data were analyzed according to emerging themes identified from the interviews; qualitative thematic analysis of the data was performed using specialist software.

Results: In interviews and focus groups, efficacy, ease of use, and lower frequency of use were favored attributes for current treatment, while side effects, medication taste, and more complex administration techniques were key dislikes. In interviews, most participants would consider a switch in medication, mainly for improved efficacy, but also to reduce medication frequency or following physician advice. Overall, efficacy and ease of use were the 2 most important attributes reported in interviews in all 3 countries.

Conclusions: Patients with COPD have preferences for certain attributes of medication, highlighting the multi-faceted nature of treatment effectiveness and the importance of the delivery device. These results were subsequently used to inform the design of a discrete choice experiment.

\footnotetext{
Abbreviations: single-inhaler triple therapy, SITT; chronic obstructive pulmonary disease, COPD; short-acting beta2-agonist, SABA; longacting beta2-agonist, LABA; long-acting muscarinic antagonist, LAMA; inhaled corticosteroid, ICS; Global initiative for chronic Obstructive Lung Disease, GOLD; multiple-inhaler triple therapy, MITT; discrete choice experiment, DCE; COPD Assessment Test, CAT; modified Medical Research Council, mMRC; health-related quality of life, HRQoL; standard deviation, SD

Funding Support: The study was funded by GlaxoSmithKline plc. (clinicaltrials.gov NCT03046069; GlaxoSmithKline plc. study CTT206455).

Date of Acceptance: August 14, 2020 | Published Online Date: November 2, 2020

Citation: Schroeder M, Hall K, Eliasson L, et al. Treatment preferences of patients with chronic obstructive pulmonary disease: results from qualitative interviews and focus groups in the United Kingdom, United States, and Germany. Chronic Obstr Pulm Dis. 202 1;8(1):19-30. doi: https://doi.org/10.15326/jcopdf.8.1.2020.0131
}

1 Value Evidence and Outcomes, GlaxoSmithKline plc., Brentford,

United Kingdom

2 Patient Centred Outcomes, ICON plc., London, United Kingdom

3 Patient Centred Outcomes, ICON plc., Abingdon, United

Kingdom

4 Value Evidence and Outcomes, GlaxoSmithKline plc., Uxbridge,

United Kingdom

Global Respiratory Therapy Area, GlaxoSmithKline plc.,

\author{
5 Brentford, United Kingdom \\ Value Evidence and Outcomes, GlaxoSmithKline plc., \\ 6 Collegeville, Pennsylvania, United States \\ Department of Health Research Methods, Evidence and Impact, \\ 7 McMaster University, Hamilton, Ontario, Canada
}




\section{This article contains an online supplement.}

\section{Address correspondence to:}

Afisi S. Ismaila, $\mathrm{PhD}$

Value Evidence and Outcomes

GlaxoSmithKline plc.

1250 South Collegeville Road

Collegeville, PA, USA 19426-0989

Phone: (919) 3158229

E-mail: afisi.s.ismaila@gsk.com

\section{Keywords:}

chronic obstructive pulmonary disease (COPD); discrete choice experiment (DCE); interview; qualitative research; treatment preferences; focus group; multi-country

\section{Introduction}

Despite the availability of current treatments, chronic obstructive pulmonary disease (COPD) is a leading cause of morbidity and mortality globally. ${ }^{1}$ Key clinical features of COPD are shortness of breath (dyspnea), cough, sputum overproduction, and exacerbations, which are defined as episodes of worsening respiratory symptoms. ${ }^{1,2}$

The aims of treatment for COPD are to alleviate symptoms, improve health status and exercise tolerance, and to reduce the frequency and severity of exacerbations. ${ }^{1}$ Currently, the main classes of inhaled treatment for COPD include beta2-adrenergic agonists (which may be short-acting beta2-agonists [SABAs] or long-acting beta2-agonists [LABAs]), long-acting muscarinic antagonists (LAMAs), and inhaled corticosteroids (ICSs). ${ }^{1}$ The Global initiative for chronic Obstructive Lung Disease (GOLD) recommends triple therapy (ICS + LAMA + LABA) for patients who are on a LAMA/LABA or ICS/LABA treatment and continue to have exacerbations. ${ }^{1}$ Triple therapy with ICS + LAMA + LABA improves lung function, patient-reported outcomes, and, in particular, exacerbation risk versus ICS/LABA in patients with COPD. ${ }^{3-7}$ Randomized clinical trials have also reported the benefit of triple therapy compared with LAMA monotherapy ${ }^{8}$ and LAMA/ LABA combination therapy. ${ }^{9,10}$

Until recently, patients were required to use at least 2 inhalers to receive inhaled triple therapy; however, single-inhaler triple therapies (SITTs) (ICS/LAMA/ LABA) are now available. ${ }^{11-13}$ Evidence shows that SITTs provide patient benefits over multiple-inhaler triple therapies (MITTs), including enhanced efficacy and lower direct costs. ${ }^{14,15}$ Higher rates of treatment persistence and adherence have been reported for patients who use a single inhaler, compared with those who use multiple inhalers, ${ }^{16}$ potentially due to increased convenience and ease of use. Such increased adherence is related to better quality of life status among patients with $\mathrm{COPD}^{17}$ and reduced health care resource utilization. ${ }^{18}$

Given the wide variety of existing treatments for COPD, which can differ in terms of the regimen and number of inhalers, an improved understanding of patient preferences may inform physician prescribing decisions. Moreover, patient perceptions are a major factor in determining treatment compliance/ adherence, which may impact on treatment efficacy and the risk of hospitalization. ${ }^{19-22}$

One well-established method of evaluating patient preferences is a discrete choice experiment (DCE). A number of studies have previously utilized this approach to quantify preferences for COPD treatments from the perspectives of patients ${ }^{23-25}$ and nurses ${ }^{26}$ in different settings. Qualitative research is required to inform the development of a DCE.

The objective of this study was to identify relevant, patient-determined attributes of COPD treatment in the United Kingdom, United States, and Germany. The relative importance of each attribute, patient preferences, priorities, and treatment goals was also explored. While obtaining valuable qualitative data on treatment preferences, this information was also used to define the relevant attributes and levels for inclusion in a subsequent online DCE, which allowed a quantitative evaluation of patient preferences and relative importance of attributes of inhaled treatments for COPD. The methodology and results for this DCE have been reported in a separate publication. ${ }^{27}$

\section{Materials and Methods}

\section{Study Populations}

Patients with a self-reported physician diagnosis of moderate-to-severe COPD were enrolled by a specialist recruitment agency (Global Perspectives) via the established channels in each country, including the recruiter's proprietary patient database, consumer recruiter networks, medical recruiter networks, support groups and nurses, as well as patient key opinion leaders and social media. Inclusion criteria were: a self-reported physician 
diagnosis of moderate-to-severe COPD, a COPD Assessment Test (CAT) score of $\geq 10$ or a modified Medical Research Council (mMRC) Dyspnea Scale score of $\geq 2$ at enrollment; current prescription of either an ICS/LABA, LABA/LAMA, or ICS + LABA + LAMA combination, or a LAMA alone; age $\geq 40$ years; current residency in the United Kingdom, United States , or Germany; adequate written and oral fluency in the language of their country of residence; and the ability to participate in an interview or focus group, including access to the internet. Individuals were excluded if they had a current diagnosis of asthma (patients with a prior history of asthma were eligible if they had a current diagnosis of COPD) or any comorbidity that would inhibit their ability to provide informed consent or participate.

In this qualitative survey analysis, the sample size was determined according to data saturation, i.e., no further interviews were conducted once no new themes or concepts were emerging. Data saturation was expected to be reached after approximately 15 interviews, therefore, a total qualitative sample of 45 patients was expected to be adequate to reach data saturation for all 3 countries. ${ }^{28}$ If saturation was not reached, the sample number would have been increased accordingly. Saturation was assessed using a documented codebook approach and saturation tables, ${ }^{28}$ documenting the rigor of the qualitative methods.

Clinical experts were recruited via Global Perspectives, using a database of individuals who had previously taken part in research or had expressed interest in doing so. The recruited clinical experts were registered clinicians in the United Kingdom, United States, or Germany, specializing in respiratory medicine and currently treating patients with COPD.

Institutional review board (Salus IRB, Texas, United States) approval of the study protocol was obtained prior to commencement. Informed consent was obtained from all participants prior to study initiation.

\section{Development of Interview and Focus Group Discussion Guides}

A targeted literature review focusing on the use of SITT and MITT in COPD was used to structure qualitative interview guides and focus group discussion guides for the patient research (Supplementary Tables S1 and S2 in the online supplement). In addition, 3 expert clinician interviews were conducted to obtain the perspective of treating physicians on relevant disease and treatment factors, including aspects of the patient experience of COPD, current treatment, patient satisfaction, ideal treatment attributes, and cost implications of treatment. This was used to refine the discussion guides intended for the patient research; no data are presented in this manuscript.

Interview topics covered the experience of current treatments, attitudes towards switching treatments, treatment preferences and priorities, treatment goals, symptoms, and health-related quality of life (HRQoL). Interview participants were also asked to individually provide what they consider to be the 3 most important attributes of COPD medication from a list (ease of use, effectiveness, frequency of use, speed of effect, impact on sleep, side effects, exacerbations, and cost) and rank them by importance on a scale of 1 to 3 , with 1 being the most important. Participants were also invited to comment on any additional important aspects of treatment that had not already been discussed.

\section{Participant Interviews and Focus Groups}

Eligible participants took part in a telephone interview or a face-to-face focus group conducted by experienced, trained interviewers from ICON plc., (United Kingdom and United States) or Global Perspectives (Germany). Interviews were conducted with a total of 30 participants, 10 from each country (United Kingdom, United States, and Germany), and 3 focus groups were conducted ( 1 per country) with a total of 16 participants (United Kingdom, n=4; United States, $n=6$; Germany, $n=6$ ). Interviews and focus groups followed distinct semi-structured interview guides and lasted approximately 60 minutes.

\section{Data Analysis}

All interviews and focus groups were audio recorded and transcribed verbatim. Each transcript was checked for quality and coded using a code book, in which codes were grouped under categories generated from topics in the interview guide. Qualitative thematic analysis of the interview data was performed by the study staff using specialist software (MAXQDA version 11, VERBI Software GmBH). The overall ranking of the top 3 attributes reported in the interviews was calculated by allocating a score based on each attribute's rank, with a ranking of first, second, and 
third allocated scores of 3,2 , and 1 , respectively (the highest ranking of importance received the highest score). The cumulative score of each attribute was then calculated and used to rank the attributes in order of overall importance.

\section{Results}

\section{Participant Characteristics}

The demographics, clinical characteristics, and current medication of participants who took part in individual interviews $(\mathrm{N}=30)$ and focus groups $(\mathrm{N}=16)$ are presented in Table 1. Overall, participants had a mean (standard deviation [SD]) age of 56.9 (10.4) years and 52.8 (9.1) years in the interviews and focus groups, respectively. There was a similar proportion of male and female interview participants (53\% and $47 \%$, respectively), but participants were predominantly male in the focus groups (75\% male versus $25 \%$ female). Regarding medication, participants were on a broad range of treatments; the most common treatments patients received as part of their regimen were ICS/LABA or SABA for patients in individual interviews (50\% each) and LAMA/ LABA for patients in the focus groups (63\%). Some patients took more than 1 treatment.

\section{Qualitative Results}

The results presented in this section cover patients' perceptions of their current treatments, attitudes towards switching treatments, and treatment preferences. Quantitative results related to the most frequently reported symptoms, HRQoL factors and other outcomes are provided in the online supplement (see Supplementary Figures S1 and S2), while illustrative participant quotes are shown in Table 2.

\section{Perception of Current Medication}

Across individual interviews, current treatments were reported and discussed. Approximately half of the interview participants (United Kingdom, $n=4 / 10$; United States, $n=5 / 10$; Germany, $n=6 / 10$ ) stated that efficacy was the most important attribute of their medication(s). Similar proportions were reported in the U.K. and U.S. focus groups, with 5 participants specifically referring to relief of symptoms. Around half of the interview participants (United Kingdom, $\mathrm{n}=3 / 10$; United States, $\mathrm{n}=7 / 10$; Germany, $\mathrm{n}=4 / 10$ ) also reported that they liked how easy their inhaler was to use, with 4 participants liking that they were able to see how many doses were left and 3 referring to the number of steps required to use their inhaler, with an apparent preference for fewer steps. Three participants also stated that they liked the frequency with which they had to take their medication, 2 of whom took their medication once daily. Similar responses regarding the frequency of medication use were reported in the U.K. and U.S. focus groups, with participants reporting that they preferred to take their medication once per day.

Regarding aspects of their current treatment that participants did not like, the largest proportion of participants stated side effects ( $n=7$ interviews and discussed by the U.K. and U.S. focus groups), followed by the taste of the medication ( $\mathrm{n}=5$ interviews and discussed by the U.S. focus group), and the lack of user friendliness of the inhaler in the context of the number of steps required for use ( $\mathrm{n}=5$ interviews). The next most disliked aspects were higher required frequency of use ( $n=4$ interviews), the powder formulation of their medication ( $n=3$ interviews), lack of efficacy ( $n=3$ interviews), and having to take medication in general ( $\mathrm{n}=3$ interviews and discussed in the U.S. and German focus groups). A total of 18 interview participants spontaneously reported the occurrence and type of side effects they had experienced with their current and previous COPD treatment, including sore throat $(n=5)$, headache $(n=4)$, and dry mouth $(n=3)$. In contrast, 12 interview participants did not think they had experienced any side effects. In the focus groups, reported side effects included dry mouth, sore throat, headache, thrush, "runny nose," and hives. Although avoiding side effects was considered important, participants reported that they could accept them if their COPD symptoms were relieved. A large proportion of participants in the interviews in the United States ( $\mathrm{n}=9 / 10)$ and 5 participants each in Germany and the United Kingdom reported that they had concerns about their current medication, specifically regarding side effects $(n=10)$, tolerability $(n=7)$, and lack of efficacy $(n=5)$. A large proportion of interview participants across the 3 countries ( $n=24 / 30$ ) stated that they would be willing to switch medication, mostly in search of improved efficacy $(n=21)$, to reduce medication frequency $(n=7)$, on advice from their doctor $(n=6)$, to increase ease of use $(n=4)$, or to reduce cost $(n=4)$. 


\section{Table 1. Demographics, Clinical Characteristics, and Current Medication of Patients in the Individual Interviews and Focus Groups}

\begin{tabular}{|c|c|c|c|c|c|}
\hline Characteristic & $\begin{array}{c}\text { Interviews } \\
(\mathrm{N}=30)\end{array}$ & $\begin{array}{l}\text { Focus } \\
\text { Groups } \\
(\mathrm{N}=16)\end{array}$ & Characteristic & $\begin{array}{c}\text { Interviews } \\
(\mathrm{N}=30)\end{array}$ & $\begin{array}{l}\text { Focus } \\
\text { Groups } \\
(\mathrm{N}=16)\end{array}$ \\
\hline Mean (SD) age, years & $56.9(10.4)$ & $52.8(9.1)$ & \multicolumn{3}{|l|}{ Highest Level of Education, n (\%) } \\
\hline \multicolumn{3}{|l|}{ Gender, $\mathrm{n}(\%)$} & No formal education & $2(7)$ & $2(13)$ \\
\hline Male & $16(53)$ & $12(75)$ & Left school at 16 with qualifications & $1(3)$ & $3(19)$ \\
\hline Female & $14(47)$ & $4(25)$ & Left school at 18 with qualifications & $7(23)$ & $0(0)$ \\
\hline \multicolumn{3}{|l|}{ Ethnicity, n (\%) } & Technical/vocational qualifications & $10(33)$ & $2(13)$ \\
\hline White & $28(93)$ & $12(75)$ & from a college or job & & \\
\hline Black or African American & $1(3)$ & $0(0)$ & Completed university & $9(30)$ & $8(50)$ \\
\hline Asian & $0(0)$ & $3(19)$ & Other & $1(3)$ & $1(6)$ \\
\hline Asian British: Indian & $0(0)$ & $1(6)$ & \multicolumn{3}{|l|}{ Smoker, n (\%) } \\
\hline Hispanic or Latino & $1(3)$ & $0(0)$ & Yes & $6(20)$ & $2(13)$ \\
\hline \multicolumn{3}{|l|}{ Employment Status, n (\%) } & No & $3(10)$ & $1(6)$ \\
\hline Employed full-time & $19(63)$ & $9(56)$ & Former & $21(70)$ & $13(81)$ \\
\hline Employed part-time & $2(7)$ & $2(13)$ & \multicolumn{3}{|l|}{ Pet Owner, n (\%) } \\
\hline Self-employed & $1(3)$ & $0(0)$ & Yes & $11(37)$ & $6(38)$ \\
\hline Seeking work & $0(0)$ & $1(6)$ & No & $15(50)$ & $6(38)$ \\
\hline Retired & $6(20)$ & $3(19)$ & Former & $4(13)$ & $4(25)$ \\
\hline Stay-at-home & $2(7)$ & $0(0)$ & \multirow{2}{*}{$\begin{array}{l}\text { Median (range) Time Since } \\
\text { Diagnosis, years }\end{array}$} & \multirow[t]{2}{*}{$5(1-20)$} & \multirow[t]{2}{*}{$5(0.75-21)$} \\
\hline Other & $0(0)$ & $1(6)$ & & & \\
\hline \multicolumn{3}{|l|}{ Marital Status, n (\%) } & \multicolumn{3}{|l|}{ Current Medication, n (\%) } \\
\hline Married & $17(57)$ & $8(50)$ & ICS/LABA & $15(50)$ & $7(44)$ \\
\hline Divorced/separated & $4(13)$ & $0(0)$ & LAMA/LABA & $5(17)$ & $10(63)$ \\
\hline Partnership & $1(3)$ & $2(13)$ & LABA & $8(27)$ & $3(19)$ \\
\hline Widowed & $1(3)$ & $0(0)$ & LAMA & $9(30)$ & $6(38)$ \\
\hline \multirow[t]{2}{*}{ Single } & \multirow[t]{2}{*}{7 (23) } & \multirow[t]{2}{*}{$6(38)$} & ICS & $2(7)$ & $1(6)$ \\
\hline & & & SABA & $15(50)$ & $3(19)$ \\
\hline
\end{tabular}

$\mathrm{SD}=$ standard deviation; ICS=inhaled corticosteroid; LABA=long-acting beta2-agonist; LAMA=long-acting muscarinic antagonist;

$\mathrm{SABA}=$ short-acting beta2-agonist

\section{Preferences for Attributes of Treatment}

Treatment preferences were also discussed. Illustrative participant quotes are presented in Table 2. Overall, a large proportion of interview participants $(n=25 / 27)$ across the countries referred to treatment effectiveness as either "important," "very important," or "extremely important." When asked to define "treatment" effectiveness, 4 interview participants referred to a treatment that "works," while other definitions were related to "symptom relief" ( $n=16$ interviews and discussed by the German focus group), and "speed of effect" ( $n=14$ interviews and discussed by the U.S. and German focus groups). References were also made to "exacerbations" (preventing occurrence and/or reducing the number/length; $n=5$ interviews and discussed by the U.K. and U.S. focus groups), "improved HRQoL" ( $\mathrm{n}=5$ interviews) and "prevention of disease progression" ( $n=5$ interviews, plus the U.S. focus group). Although preference for "speed of effect" of medication (rescue or maintenance) varied in interviews, "fast" ( $n=6)$ and "immediately" ( $n=5)$ were the most common responses.

Ease of use was reported in interviews to be an important aspect of medication; this included the number of steps required to use an inhaler $(n=13)$, with an apparent preference for fewer steps, and the size and shape of an inhaler $(n=10)$, with 8 participants stating a preference for a smaller inhaler. While the length of time that participants stated it took them to use their inhaler ranged from seconds (2-30 seconds, 


\section{Table 2. Illustrative Patient Quotes ${ }^{\mathrm{a}}$}

Topic Symptoms

Description

\section{Example Quote}
"Lightheaded and very chesty, very 'mucusy' in the chest, that type of thing. That is it, in the main, really" (United Kingdom).
"My main symptoms are definitely - and I'm probably going to cough through this interview, so you'll have to excuse me. It's definitely coughing and being out of breath, heaviness in my chest, wheezing, particularly if I do anything in any way physical that I don't usually do" (United States).
"And my lungs generally frequently don't feel clear. You know, I always feel like you could clear your throat but, you know, I feel like I have something in it. I seem to start getting, like, chest infections more frequently, but then I get real careful when that occurs" (United States).
"I would - you know, generally I feel weak" (United States).

Health-Related "If I was very breathless, yes, it would be every time. Like, even putting on my socks and shoes, I

Quality of Life struggle because I feel as if my stomach's squashing my lungs. That would be the best way to describe it" (United Kingdom).

"Generally, I fall asleep easily and I have a deep sleep but sometimes I suddenly wake up and have a coughing attack. Everything is congested with mucus and I have to get up. Sometimes I am awake up to 1 hour and I have to take my medication. This is really disturbing and I experience it about 5 to 6 times per week. Maybe there is one night when I have a good night's sleep" (Germany).

"Well, I can't be involved too much with any physical activity that's, like, sports related. I can't play basketball. I mean, I don't even try. I mean, I tried and it just makes me, you know, wheeze, you know, out of breath. And I couldn't do hikes and I can't do, like, I can't do any sprints, but I can do, like, light jogging, but I can't do it for a long period of time and can only do - so very limited. It just restricts my activities. So, it's - that's frustrating to me. I don't like that" (United States focus group).

"I go to a lot of family events. I've got - I belong to a big family and when you're having, yeah, you know, a flare-up, it's embarrassing. You have to go away, because they, "Hey, is he okay, is everything should we call 911 ?" I'm like, "No, I'm okay." And then to have to explain that, that's a little bit tiring and it's embarrassing" (United States focus group).

"I mean, you guys, I don't know anybody here, but I'm just going to throw it out there because...I have a great wife, but it's like 1 in 4 times, or 1, maybe 2 times, it's like, I - you know, the issue with like, I really feel like something's squeezing my - something and it's, like, it won't - I want to, like, take something and the medicine doesn't affect it, but there's something squeezing my airways and it's like I'm trapped. That's how I feel and like she said, you know, it causes the panic, you know. But that's the - that's probably the worst thing for me is that part of - that aspect of it, 'cause it's like, I got - if I didn't have a patient wife, I'd be divorced, you know. Actually, I'm just throwing it out there" (United States focus group).

\section{Current Treatment}

Description "Yeah, it's - one of the things I do like about it is, I take it once a day. It's pretty easy to take. You just, kind of, flip it open, breathe in slowly, and count to, like, I don't know, 5 or 7 and then breathe out and that is my, what I call my maintenance inhaler" (United States).

"Well, I take a - I use a pump and really, I mean, it does work and it's not curing the COPD, but it's clearing the airways so I can start to breathe properly. So, yes, it's - but it is a, sort of, Elastoplast cure, isn't it?" (United Kingdom focus group).

"I'm okay about using it, but I really don't see the effects from it, whether it's because I'm taking it and it is having [an] effect and I don't realize it" (United Kingdom).

"Well, you know, I mean, it's like the best thing that I have to use right now. There's nothing better that I have" (United States).

"Concerns? Rather not. I don't worry too much about it, I hope in the back of my mind that the pharmaceutical industry will produce pharmaceuticals soon, which are maybe more effective, better, 
with better results" (Germany).

[Anything else about it that concerns you?] "No, not necessarily, "cause that would be, like, my main concern, you know, like bad side effects of course" (United States).

"I think that it's always a concern with everybody is that your body's going to start to become immune to it, because it's, you know, it's so used to it that it's not going to function anymore with it" (United States).

Switching "Well, right now you would have to prove to me that this new drug would have some big improvement over what I'm feeling now [...] I would have more energy. I'd be able to breathe better [...] you take it once a day. The benefit for me would be taking it once a day, or if it's some kind of release, where it was released over time" (United States).

"No, just if somebody said to me there's a new medicine they're trying out that they say that it's very good and it's more beneficial, I'd be begging for it" (United Kingdom).

"I would switch treatments if they could find a treatment that would cure it. But otherwise, there's no point in me switching treatments, 'cause what I'm taking once a day does work. So, it's - yeah. So, unless they're going to come up with something that actually - and so far, they haven't come up with anything that cures it totally" (United Kingdom focus group).

\section{Treatment Preferences}

Treatment "I mean, if it's not effective then what's the point, you know?" (United States).

Effectiveness "Oh, that [treatment effectiveness], 100 out of 100. I mean, that's what it's really all about" (United States).

Exacerbations "I mean, that's the main thing, trying to avoid a flare-up, you know?" (United Kingdom focus group). "I just have to stop what I'm doing. Just completely stop what I'm doing and get my rescue inhaler. Use it and just stop what I'm doing, until it takes effect" (United States).

Ease of Use "Yeah, I mean, the inhaler ease of use, it's got to be easy to use, you know, 'cause it's not - yeah, it's got to be easy to use. It's your breathing, you know..." (United Kingdom focus group).

"Not having to prick it but only open something, breathe in, and close it and be done" (Germany).

Medication

Frequency "I wish I didn't have to take it every day. I wish - I'm happy that it's only once a day, compared to 2 times a day or 3 times a day, so that part I'm happy with. I wish I could take it once a week. I wish I could take it once a month. That would make me even happier. You know, that's another thing psychologically, every time I take it, it reminds me that I have this medical disease. It just reminds me again that I'm living with this, which is a real downer" (United States).

Number of "Now I got 3 different pharmaceuticals applied with 3 different inhalers, naturally it would be Inhalers better to take only 1 inhaler and 1 pharmaceutical" (Germany).

Side Effects "I'm not really too bothered about side effects and I would rather cope with side effects than cope with breathlessness" (United Kingdom).

"Nobody needs side effects because the disease itself keeps you busy enough and if you additionally have to deal with side effects it would be tough as you would have to decide with which you deal first: your disease or the side effects" (Germany).

Costs "A little more money for a lot more efficiency, sure. A little bit of money - 'cause money is a huge factor" (United States focus group).

${ }^{\mathrm{a}}$ quotes are from individual interviews unless otherwise indicated $\mathrm{COPD}=$ chronic obstructive pulmonary disease

$\mathrm{n}=12$ interviews) to minutes ( 1 minute, $\mathrm{n}=2$ interviews; 2-5 minutes, $\mathrm{n}=10$ interviews), no participants stated that they had a problem with the length of time it took to use their device. Across the 3 countries, most interview participants $(n=26)$ stated that they would prefer to take their medication less often, with participants in the U.K. focus group stating once per day, while participants in the U.S. focus group stated a preference for less than once per day. The majority of interview participants indicated that they would prefer either a 1- or 2-inhaler treatment regimen ( $n=19$ interviews). The remainder would prefer not 
to use any inhalers (participants that preferred oral tablet formulations: $n=2)$, use 3 inhalers $(n=1)$, or did not specify a preference $(n=5)$.

\section{Cost Implications}

While medication costs vary greatly across and within countries, interview participants reported in general that they would be willing to pay more for their medication for increased efficacy ( $n=16$, plus participants in the focus groups in the United Kingdom, United States, and Germany), fewer, or no, side effects $(n=5)$, increased ease of use $(n=4)$, and once-a-day frequency $(n=4)$.

\section{Attribute Ranking}

When interview participants were asked to rank attributes of medication by importance, efficacy and ease of use were the 2 most important attributes in all 3 countries, with speed of effect (United Kingdom), cost (United States), and side effects (Germany) ranked third (Table 3).

\section{Attributes Identified as Relevant for the DCE}

Six treatment attributes were identified as being appropriate for inclusion in a subsequent DCE, each with 3 associated levels, indicated in parentheses. These were ease of use (likely to make no/some/a lot of mistakes); exacerbations (likely to have no exacerbations/ 1 exacerbation/2 exacerbations in the next year); number of times per day required to take the medication ( $1 / 2 / 3$ times); number of inhalers $(1 / 2 / 3)$; side effects (likely to experience no/some/a lot of side effects); and out-of-pocket costs per month (no change/5\% decrease/10\% decrease; Germany and United States only, as treatment cost is not relevant in the United Kingdom [most patients with COPD in the United Kingdom pay a standard perprescription fee, regardless of treatment type]).

\section{Discussion}

This study provides a unique perspective and helps to further our understanding of the preferences that patients with COPD have for attributes of their treatment. It employed a cross-country analysis to understand if, and how, participant opinions differ across different countries (United Kingdom, United States, and Germany), to provide a broader perspective compared with previous single-country studies. ${ }^{29-31}$ Focus groups were included to supplement the individual interviews and to allow further elaboration through patient-to-patient interactions.

As anticipated, individuals with COPD had preferences for certain attributes relating to improvement of their medication, the most prominent of which were efficacy in reducing symptoms, ease of

\section{Table 3. Ranking of COPD Treatment Attributes by Country from Individual Interviews}

\begin{tabular}{|c|c|c|c|}
\hline Rank & United Kingdom & United States & Germany \\
\hline$\underline{1}$ & Ease of use & Efficacy & Efficacy \\
\hline$\underline{2}$ & Efficacy & Ease of use & Ease of use \\
\hline 3 & Speed of effect & Cost & Side effects \\
\hline 4 & Medication frequency & Side effects & Reduction of sleep disturbance \\
\hline 5 & Reduction of exacerbation frequency & Speed of effect & Reduction of exacerbation frequency \\
\hline 6 & Number of inhalers & Reduction of sleep disturbance & Medication frequency \\
\hline 7 & Reduction of sleep disturbance & Reduction of exacerbation frequency & Speed of effect \\
\hline 8 & Side effects & & Cost \\
\hline $\begin{array}{l}\text { Not } \\
\text { ranked } \\
\text { by any } \\
\text { patient }\end{array}$ & Cost & $\begin{array}{l}\text { Medication frequency } \\
\text { Number of inhalers }\end{array}$ & Number of inhalers \\
\hline
\end{tabular}

Ease of use and efficacy were ranked first or second in each country (underlined)

Not all patients provided 3 attributes

$\mathrm{COPD}=$ chronic obstructive pulmonary disease 
use, few side effects, and fast onset of effect. While side effects are an important consideration and are preferably avoided, participants appeared willing to make a trade-off and accept some side effects if a medication could effectively reduce COPD symptoms. Most, but not all, participants indicated that they would be prepared to switch to a new treatment option with improved attributes, especially one offering enhanced efficacy and fewer side effects.

Responses were broadly similar between different countries, though there was some variation in preference for particular attributes. When asked to rank attributes by importance, efficacy and ease of use were the 2 most important in all 3 countries, though the attribute ranked third varied (speed of effect in the United Kingdom, cost in the United States, and side effects in Germany). Most interview participants stated that they would prefer to take their medication less often, though the U.K. focus group preferred once per day and the U.S. group preferred less than once per day.

While the medication preferences of participants with COPD have previously been evaluated, ${ }^{29-31}$ the treatment landscape has since changed considerably. It is, therefore, important to re-evaluate participant preferences in the context of newer treatments that offer the possibility of improved efficacy, more convenient dosing, and the need for fewer inhalers.

The importance of each of the positive attributes consistently identified across all 3 countries (efficacy in reducing symptoms, ease of use, few side effects, and fast onset of effect), along with other important factors highlighted in this study, such as frequency of use and cost, has previously been reported for individuals with COPD and asthma. ${ }^{29-31}$ Telephone interviews and focus groups of patients with asthma and $\operatorname{COPD}(\mathrm{N}=72)$ in a U.K. study revealed that treatment preferences were linked to reducing the impact of disease, with improved sleep, and speed of onset and duration of treatment effect highlighted as key factors of treatment. ${ }^{30}$ Quantitative findings from a study of adult patients with COPD $(\mathrm{N}=300)$ in Germany investigating disease-related preferences also highlighted the importance of reducing disease impact, through reduced breathlessness, and improved sleep quality and performance capability. Conversely, onset, frequency of use, and the emotional effects of medication were considered to be of minor importance. $^{31}$
This study had some limitations. Participants selfreported a physician diagnosis of moderate-to-severe COPD coupled with CAT or mMRC dyspnea scores that indicated significantly impaired heath status or breathlessness-induced disability: there was no clinician confirmation of the diagnosis for the study. However, a detailed screening script was employed by the recruiting agencies in order to avoid potential patient misrepresentation where possible. In addition, treatment patterns and symptoms described by the patients during the research were consistent with the COPD population, ${ }^{32,33}$ indicating the included patients represent an appropriate sample for this population.

The recruitment techniques, small patient samples and qualitative methodologies used mean that the results may be of limited generalizability to the wider COPD patient population. As an example, the gender of patients in the focus groups was predominantly male (75\%), which may have affected the overall perception of the most important treatment attributes. It should be noted, however, that the results of the focus groups were similar to those from the individual interviews, in which gender was more balanced. Furthermore, the participants recruited for the interviews and focus groups were notably younger than the typical clinical population of patients with COPD: previous meta-analyses have estimated that COPD is most prevalent in older age groups ( $\geq 60$ years of age), ${ }^{34,35}$ while the mean ages of the participants in these interviews and focus groups were 56.9 years and 52.8 years, respectively. For this reason, extrapolation of these preferences to older patient populations should be approached with caution. The subsequent $\mathrm{DCE},{ }^{27}$ informed by the present results, provides quantitative data on patient preferences and the relative importance of COPD treatment attributes in larger patient populations from the 3 countries and may, therefore, be expected to include a broader patient population and have greater generalizability.

Additionally, recruitment of participants from a database of individuals who had previously taken part in research, or had expressed interest in doing so, may have created selection bias, which again could limit the wider application of these findings. The proportions of patients with higher level education (30\% and $50 \%$ in interviews and focus groups, respectively, had completed university) were greater than may be 
expected in a broad COPD population. In a previous DCE in patients with COPD, which recruited patients from an opt-in internet survey panel, levels of higher education were similarly high, with $39 \%$ of patients having attended college and $31 \%$ of patients with a college or higher degree. ${ }^{36}$ Selection bias may have also had an impact on the diversity of patients who participated in the focus groups: patients with more severe COPD may not have been able or willing to travel to take part in these discussions.

In other studies, a sample size of 10 participants per country with a total of 30 may be considered small; however, as a qualitative survey analysis, the sample size was determined through assessment of saturation on the data already collected, as described by Kerr et al. ${ }^{28}$ A total of 45 patients for all 3 countries was expected to be sufficient to reach saturation but, in practice, saturation was reached with a population size of 30 patients (10 per country).

This study was conducted to elicit aspects of care that patients deem important. The results of our study also provide valuable insight into the parameters most appropriate for inclusion in a future DCE. A DCE is an effective quantitative method for evaluating treatment preferences. For example, a DCE performed in the United States ( $N=515)$ reported that efficacy and safety were the most important attributes to COPD patients, and that less frequent use of rescue medication, overall ease of use, and perceived speed of effect were also important. ${ }^{29}$ Similarly, our study resulted in the inclusion of the following as attributes in our future DCE: number of exacerbations (efficacy), number of times per day medication is required (frequency of use), and side effects (safety), in addition to number of inhalers and ease of use.

\section{Conclusion}

This study provides a valuable up-to-date insight into the medication attributes that are important to patients with COPD in the United Kingdom, United States, and Germany, particularly given the availability of newer treatments such as SITTs. Results indicate that for patients with COPD in these countries, efficacy and safety remain priorities, whilst also revealing the importance of ease and frequency of use, and number of inhalers required. These results informed the definition of relevant attributes and levels for inclusion in a subsequent online DCE, ${ }^{27}$ which provides further valuable information on treatment preferences of patients with COPD.

Patient perception of "treatment effectiveness" is multi-faceted, considering factors such as speed of onset/duration of effect, HRQoL, symptom relief, exacerbation reduction, and prevention of disease progression. Health care providers should support patients by considering the key attributes that are important to each individual, with the aim of improving adherence and, thus, overall treatment effectiveness.

\section{Acknowledgments}

The authors would like to thank Helen Doll, Hannah Lewis, and Sam Llewellyn from ICON plc., for providing support with this qualitative work, reviewing early drafts of this manuscript, and undertaking the subsequent DCE. We also acknowledge and thank the individuals who participated in the study and Global Perspectives, Oviedo, Spain, for participant recruitment.

Author contributions: Author contributions were as follows: MS, KH, LE, NG, JM, PJ, and ASI take responsibility for the study conception or design. MS, KH, LE, SB, JM, and ASI take responsibility for data collection. All authors take responsibility for data analysis or interpretation, writing/reviewing, and final approval of the manuscript.

\section{Declaration of Interest}

Editorial support (in the form of writing assistance, collating author comments, assembling tables/figures, grammatical editing and referencing) was provided by Tom Gallagher, PhD, and Molly Macpherson, BSc, of Gardiner-Caldwell Communications (Macclesfield, United Kingdom) and by Chrystelle Rasamison, of Fishawack Indicia, and was funded by GlaxoSmithKline plc.

The authors declare the following conflicts of interest during the last 3 years in relation to this article: MS, ASI, NG, and PJ are employees of, and hold shares in, GlaxoSmithKline plc. ASI is also unpaid faculty at McMaster University, Canada. SB, $\mathrm{LE}, \mathrm{KH}$, and JM were employees of ICON plc., while the study was conducted. ICON plc., received funding from GlaxoSmithKline plc., to conduct this study but were not paid for the development of this publication. 


\section{References}

1. Global Initiative for Chronic Obstructive Lung Disease (GOLD). Global strategy for the diagnosis, management, and prevention of chronic obstructive pulmonary disease. 2019 report. GOLD website. Published November 2018. Accessed March 11, 2019. https:// goldcopd.org/wp-content/uploads/2018/11/GOLD-2019-v1.7FINAL-14Nov2018-WMS.pdf

2. Wedzicha JA, Miravitlles M, Hurst JR, et al. Management of COPD exacerbations: a European Respiratory Society/American Thoracic Society guideline. Eur Respir J. 2017;49(3):pii:1600791. doi: https://doi.org/10.1183/13993003.00791-2016

3. Singh D, Brooks J, Hagan G, Cahn A, O'Connor BJ. Superiority of "triple" therapy with salmeterol/fluticasone propionate and tiotropium bromide versus individual components in moderate to severe COPD. Thorax. 2008;63(7):592-598. doi: https://doi.org/10.1136/thx.2007.087213

4. Frith PA, Thompson PJ, Ratnavadivel R, et al. Glycopyrronium oncedaily significantly improves lung function and health status when combined with salmeterol/fluticasone in patients with COPD: the GLISTEN study, a randomised controlled trial. Thorax. 2015;70(6):519527. doi: https://doi.org/10.1136/thoraxjnl-2014-206670

5. Siler TM, Kerwin E, Singletary K, Brooks J, Church A. Efficacy and safety of umeclidinium added to fluticasone propionate/salmeterol in patients with COPD: results of two randomized, double-blind studies. COPD. 2016;13(1):1-10.

doi: https://doi.org/10.3109/15412555.2015.1034256

6. Singh D, Papi A, Corradi M, et al. Single inhaler triple therapy versus inhaled corticosteroid plus long-acting beta2-agonist therapy for chronic obstructive pulmonary disease (TRILOGY): a double-blind, parallel group, randomised controlled trial. Lancet. 2016;388(10048):963-973.

doi: https://doi.org/10.1016/S0140-6736(16)31354-X

7. Lipson DA, Barnacle H, Birk R, et al. FULFIL trial: once-daily triple therapy for patients with chronic obstructive pulmonary disease. Am J Respir Crit Care Med. 2017;196(4):438-446. doi: https://doi.org/10.1164/rccm.201703-0449OC

8. Vestbo J, Papi A, Corradi M, et al. Single inhaler extrafine triple therapy versus long-acting muscarinic antagonist therapy for chronic obstructive pulmonary disease (TRINITY): a double-blind, parallel group, randomised controlled trial. Lancet. 2017;389(10082):19191929. doi: https://doi.org/10.1016/S0140-6736(17)30188-5

9. Lipson DA, Barnhart F, Brealey N, et al. Once-daily single-inhaler triple versus dual therapy in patients with COPD. $N$ Engl $J$ Med. 2018;378(18):1671-1680.

doi: https://doi.org/10.1056/NEJMoa1713901

10. Papi A, Vestbo J, Fabbri L, et al. Extrafine inhaled triple therapy versus dual bronchodilator therapy in chronic obstructive pulmonary disease (TRIBUTE): a double-blind, parallel group, randomised controlled trial. Lancet. 2018;391(10125):1076-1084.

doi: https://doi.org/10.1016/S0140-6736(18)30206-X
11. Trimbow Summary of Product Characteristics (SmPC). Electronic Medicines Compendium website. Updated February 8, 2019. Accessed July 4, 2019. https://www.medicines.org.uk/emc/product/761

12. Trelegy Summary of Product Characteristics (SmPC). Electronic Medicines Compendium website. Updated November 21, 2018. Accessed July 4, 2019.

https://www.medicines.org.uk/emc/product/8666

13. Lipworth B, Kuo CR, Jabbal S. Current appraisal of single inhaler triple therapy in COPD. Int $J$ Chron Obstruct Pulmon Dis. 2018;13:30033009. doi: https://doi.org/10.2147/COPD.S177333

14. Schroeder M, Guyot P, Thano A, et al. Comparative efficacy of a new single inhaler triple therapy versus alternative triple therapy combinations in patients with COPD: a systematic literature review and network meta-analysis. Poster presented at: COPD11; June 2021, 2018; Birmingham, United Kingdom.

15. Schroeder M, Shah D, Risebrough N, Ndirangu K, Martin AA, Ismaila A. Cost-minimization analysis of adding a new single inhaler triple therapy (SITT) for the treatment of patients with chronic obstructive pulmonary disease (COPD) in the UK. Value Health. 2018;21:S235. doi: https://doi.org/10.1016/j.jval.2018.04.1595

16. Yu AP, Guerin A, Ponce de Leon D, et al. Therapy persistence and adherence in patients with chronic obstructive pulmonary disease: multiple versus single long-acting maintenance inhalers. JMed Econ. 2011;14(4):486-496. doi: https://doi.org/10.3111/13696998.2011.594123

17. Takemura M, Mitsui K, Itotani R, et al. Relationships between repeated instruction on inhalation therapy, medication adherence, and health status in chronic obstructive pulmonary disease. Int J Chron Obstruct Pulmon Dis. 2011;6:97-104. doi: https://doi.org/10.2147/COPD.S16173

18. Toy EL, Beaulieu NU, McHale JM, et al. Treatment of COPD: relationships between daily dosing frequency, adherence, resource use, and costs. Respir Med. 2011;105(3):435-441. doi: https://doi.org/10.1016/j.rmed.2010.09.006

19. George J, Kong DC, Thoman R, Stewart K. Factors associated with medication nonadherence in patients with COPD. Chest. 2005;128(5):3198-3204.

doi: https://doi.org/10.1378/chest.128.5.3198

20. Mullerova H, Landis SH, Aisanov Z, et al. Health behaviors and their correlates among participants in the Continuing to Confront COPD International Patient Survey. Int J Chron Obstruct Pulmon Dis. 2016;11:881-890. doi: https://doi.org/10.2147/COPD.S102280

21. Makela MJ, Backer V, Hedegaard M, Larsson K. Adherence to inhaled therapies, health outcomes and costs in patients with asthma and COPD. Respir Med. 2013;107(10):1481-1490. doi: https://doi.org/10.1016/j.rmed.2013.04.005 
22. Krauskopf K, Federman AD, Kale MS, et al. Chronic obstructive pulmonary disease illness and medication beliefs are associated with medication adherence. COPD. 2015;12(2):151-164.

doi: https://doi.org/10.3109/15412555.2014.922067

23. Svedsater H, Leather D, Robinson T, Doll H, Nafees B, Bradshaw L. Evaluation and quantification of treatment preferences for patients with asthma or COPD using discrete choice experiment surveys. Respir Med. 2017;132:76-83.

doi: https://doi.org/10.1016/j.rmed.2017.09.010

24. Hawken N, Torvinen S, Neine ME, et al. Patient preferences for dry powder inhaler attributes in asthma and chronic obstructive pulmonary disease in France: a discrete choice experiment. BMC Pulm Med. 2017;17(1):99.

doi: https://doi.org/10.1186/s12890-017-0439-x

25. Chouaid C, Germain N, De Pouvourville G, et al. Patient preference for chronic obstructive pulmonary disease (COPD) treatment inhalers: a discrete choice experiment in France. Curr Med Res Opin. 2019;35(5):785-792.

doi: https://doi.org/10.1080/03007995.2019.1574507

26. Bogelund M, Hagelund L, Asmussen MB. COPD-treating nurses' preferences for inhaler attributes - a discrete choice experiment. Curr Med Res Opin. 2017;33(1):71-75.

doi: https://doi.org/10.1080/03007995.2016.1238353

27. Lewis HB, Schroeder M, Gunsoy NB, et al. Evaluating patient preferences of maintenance therapy for the treatment of chronic obstructive pulmonary disease: a discrete choice experiment in the UK, USA and Germany. Int JChron Obstruct Pulmon Dis. 2020;15:595604. doi: https://doi.org/10.2147/COPD.S221980

28. Kerr C, Nixon A, Wild D. Assessing and demonstrating data saturation in qualitative inquiry supporting patient-reported outcomes research. Expert Rev Pharmacoeconomics Outcomes Res. 2010;10(3):269-281. doi: https://doi.org/10.1586/erp.10.30

29. Kawata AK, Kleinman L, Harding G, Ramachandran S. Evaluation of patient preference and willingness to pay for attributes of maintenance medication for chronic obstructive pulmonary disease (COPD). Patient. 2014;7(4):413-426.

doi: https://doi.org/10.1007/s40271-014-0064-1

30. Svedsater H, Roberts J, Patel C, Macey J, Hilton E, Bradshaw L. Life impact and treatment preferences of individuals with asthma and chronic obstructive pulmonary disease: results from qualitative interviews and focus groups. Adv Ther. 2017;34(6):1466-1481. doi: https://doi.org/10.1007/s12325-017-0557-0

31. Pisa G, Freytag S, Schandry R. Chronic obstructive pulmonary disease (COPD) patients' disease-related preferences: a study using conjoint analysis. Patient. 2013;6(2):93-101. doi: https://doi.org/10.1007/s40271-013-0007-2
32. Kulich K, Keininger DL, Tiplady B, Banerji D. Symptoms and impact of COPD assessed by an electronic diary in patients with moderate-tosevere COPD: psychometric results from the SHINE study. Int J Chron Obstruct Pulmon Dis. 2015;10:79-94. doi: https://doi.org/10.2147/COPD.S73092

33. Global Initiative for Chronic Obstructive Lung Disease (GOLD). Global strategy for the diagnosis, management, and prevention of chronic obstructive pulmonary disease. 2020 report. GOLD website. Published November 2019. Accessed May 28, 2020. https://goldcopd.org/wpcontent/uploads/2019/11/GOLD-2020-POCKET-GUIDE-FINALpgsized-wms.pdf

34. Varmaghani M, Dehghani M, Heidari E, Sharifi F, Moghaddam SS, Farzadfar F. Global prevalence of chronic obstructive pulmonary disease: systematic review and meta-analysis. East Mediterr Health $J$. 2019;25(1):47-57. doi: https://doi.org/10.26719/emhj.18.014

35. Halbert RJ, Natoli JL, Gano A, Badamgarav E, Buist AS, Mannino DM. Global burden of COPD: systematic review and meta-analysis. Eur Respir J. 2006;28(3):523-532. doi: https://doi.org/10.1183/09031936.06.00124605

36. Kawata AK, Kleinman L, Harding G, Ramachandran S. Evaluation of patient preference and willingness to pay for attributes of maintenance medication for chronic obstructive pulmonary disease (COPD). Patient. 2014;7:413-426.

doi: https://doi.org/10.1007/s40271-014-0064-1 